through it. The filtrate was collected in a separate receiver, and washing with benzol continued until a colourless filtrate was again obtained. This cycle of operations was repeated with chloroform. Different fractions of oils obtained by evaporating the extracts were dissolved in chloroform and the fluorescence of the solutions compared at equal concentrations. Capillary analysis was then carried out. Some results are given in the accompanying table and chart.

The oil samples gave blue fluorescence when dissolved in chloroform; but the fractions separated by chromatography showed marked differences in fluorescence colour.

These investigations have been carried out with the aid of a grant from the Assam Oil Co., Ltd. The method is being developed further. Our thanks are due to Mr. P. Evans and Mr. A. Reid for their help.

\section{J. N. MUKHERJEE.}

\section{K. INDRA*.}

Physical Chemistry Laboratory,

University College of Science and Technology, 92 Upper Circular Road, Calcutta.

* Research scholar appointed by the Assam Oil Co., Ltd.

1 Bentz and Strobel, Proc. World Petroleum Congress, Vol. 1, 334 (1933).

2 Balada, Petroleum, 31, No. 48, 11 (1935).

a Fabian, O l. u. Kohle, 39, 631 (1943).

4 Grader, Oel. u. Kohle, 38, 867 (1942).

\section{Amides, Imides and Peptides}

IN suggesting the term 'polypeptides' for describing condensates of amino-acids at large, Dr. Jordan Lloyd $^{1}$ is seemingly extending the meaning of the word beyond that originally proposed by Emil Fischer ${ }^{2}$, who introduced it for the condensates of $\alpha$-amino-acids. Indeed, 'peptide' was not proposed for the link - CONH - but for the residue - $\mathrm{CH} R-\mathrm{CO}-\mathrm{NH}-$, as is indicated by the use of 'dipeptide' for glycylglycine, which contains only one-CONH--group. Fischer, in his original lecture ${ }^{3}$, put forward the proposal that by analogy with known distinctions made in carbohydrates between disaccharides, trisaccharides, etc., compounds of the glycylglycine type should be termed dipeptides and the higher condensates of amino-acids termed tripeptides, tetrapeptides, etc.

Dr. Jordan Lloyd's proposal, in addition to depart. ing from Fischer's original conception which has been preserved in general usage, would bring within the scope of the term such polycondensates as those obtained from $\omega$-amino-acids, for example, $\omega$-aminocaproic acid. We agree that it is desirable to avoid confusion between proteins and nylons, but we think that Dr. Lloyd's suggestion would lead to more confusion in that it would not help in differentiating between condensates of $\alpha$-amino-acids and those of $\omega$-amino-acids, which must be classed as nylons ${ }^{4}$.

It is misleading to say that nylon chemistry has its origins in organic chemistry: it is a part of organic chemistry, and not a different subject. Dr. Lloyd's complaint would seem to be based on a lack of knowledge of recent history. The word nylon is used as a short generic term ${ }^{5}$ for what the inventor of the compounds, Carothers, described, prior to the introduction of the word nylon, as polyamides ${ }^{6}$; that is, the term polyamide is older than the term nylon.
To call the group $-\mathrm{CO}-\mathrm{NH}-$ an amide or amido group is not wrong: to quote from the "Instructions to Abstractors" of the Chemical Society (see also ref. 7) "when . . . the $\mathrm{NH}_{2}$ group is substituted with an acid residue such as acetyl it becomes acetamido, etc.".

Dr. Jordan Lloyd's definition of an imine as a compound containing the $>\mathrm{NH}$ group only represents general usage when the group is part of a cyclic systern, for example, as in ethylene-imine and cyclohexamethyleneimine, or present as a : $\mathrm{C}=\mathrm{NH}$ group. Similarly, imides are cyclic secondary amides of dibasic acids ${ }^{8}$.

We agree with Dr. Jordan Lloyd that it is not so easy to use existing terms, or to devise new terms, for purposes of classification in organic chemistry as it is in, for example, botany ; but we do not agree that clarity will be brought into any relations when 'polyimide' is suggested as a general term with a definition which would seemingly include the wellknown hydroxynaphthoic arylamides.

It is an objection to polyamide that it offers itself as a generic term also for the polymers of methacrylamide $\mathrm{CH}_{2}: \mathrm{C}\left(\mathrm{CH}_{3}\right)-\mathrm{CO} . \mathrm{NH}_{2}$ but, we think, few oneword terms are used without a context.

\section{R. J. W. REynotos.}

Research and Patent Departments,

$$
\text { W. A. Silvester. }
$$

Imperial Chemical Industries, Ltd., Dyestuffs Division, Blackley, Manchester.

${ }^{1}$ Lloyd, D. Jordan, Nature, 154, 486 (1944).

2 Fischer, E., Ber., 36, 2094 (1903).

${ }^{3}$ Chem.-Zeitung, 28, 939, No. 80 (1902).

Brit. Pat. 461,236 and Brit. Pat. 461,237.

s Hoff, Ind. Eng. Chem., 82, 1560 (1940). Loasby, J. Text. Inst., 34 P'45 (1943).

'Carothers and Hill, $J$. Amer. Chem. Soc., 54, 1566 (1932), reproduced in "Collected Papers of Wallace Hume Carothers" (New York, 1944), p. 165

${ }^{7}$ Smith, J. Chem. Soc., 1076 (1936).

8 Sidgwick's "Organic Chemistry of Nitrogen", Taylor and Baker, p. 152 (Oxford Univ. Press, 1942).

DR. JoRDAN LLOYD is wrong in her conception of the nomenclature of imides and imines. While organic chemists will agree with her dictum that substances carrying the $-\mathrm{NH}_{2}$ group are amines, those which carry the $>\mathrm{NH}$ group are not necessarily imines. Thus, dimethylamine, $\left(\mathrm{CH}_{3}\right)_{2} \mathrm{NH}$, has such a group, and is still an amine; surely an imine must contain the structure $>\mathrm{C}=\mathrm{N}-$, as in the imino-ethers

$$
R_{1} \cdot \mathrm{C}_{\mathrm{O} R_{2}}^{\mathrm{NH}}
$$

With imides and amides the problem is similar; if Dr. Jordan Lloyd is correct in her view, any substance containing the - $\mathrm{CONH}-$ group would be an imide. Thus, on conversion of acetamide, $\mathrm{CH}_{3} \mathrm{CONH}_{2}$, to its methyl derivative $\mathrm{CH}_{3}$.CO.NH.CH , a change in nomenclature would also take place, and the substance would be known as 'methyl acetimide'. This is quite in opposition to current practice and would be a most undesirable feature of nomenclature. Such substances are properly known as 'substituted amides'. The conception associated with imides dates from the recognition by Wurtz ${ }^{2}$ in 1854 that amides could react as if derived from either of the structures I or II, and this persists in the 'lactam-lactim' nomen- 